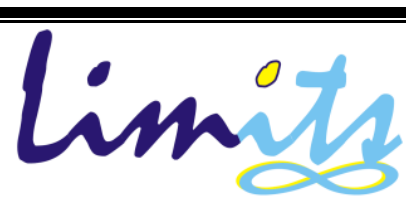

Journal of Mathematics and Its Applications

E-ISSN: 2579-8936

P-ISSN: 1829-605X

Vol. 16, No. 1, Agustus 2019, 51-61

\title{
Ring Q-Fuzzy Smarandache dan Ideal Q-Fuzzy Smarandache Beserta Sifat-Sifatnya
}

\author{
Fatmawati Hidayat $^{1}$, Marjono ${ }^{2}$, Noor Hidayat ${ }^{3}$ \\ ${ }^{1}$ Mahasiswa S2 Matematika, Fakultas MIPA Universitas Brawijaya \\ 2,3 Jurusan Matematika, Fakultas MIPA Universitas Brawijaya \\ e-mail: ${ }^{1}$ fatmawatihidayat.fifi@gmail.com
}

\begin{abstract}
Abstrak
Aljabar abstrak adalah ilmu aljabar yang membahas tentang struktur aljabar. Salah satu perluasan konsep struktur aljabar adalah struktur aljabar fuzzy. Pengembangan teori terkait struktur aljabar fuzzy telah banyak diteliti, diantaranya ring fuzzy Smarandache dan ideal fuzzy Smarandache. Ring Smarandache adalah generalisasi dari ring yang didefinisikan sebagai suatu ring yang memuat himpunan bagian sejati $A \subset R$ berbentuk field dan ideal Smarandache didefinisikan sebagai suatu ideal $A$ dari $R$ yang memuat himpunan bagian sejati $X \subset A$ berbentuk field. Penelitian ini bertujuan untuk mengembangkan struktur aljabar Q-fuzzy Smarandache karena belum banyak penelitian terkait struktur tersebut. Permasalahan tersebut kemudian digunakan untuk membangun struktur baru tentang ring Qfuzzy Smarandache dan ideal Q-fuzzy Smarandache beserta sifat-sifatnya. Struktur baru ini dibentuk berdasarkan definisi ring fuzzy Smarandache dan ideal fuzzy Smarandache serta sifat-sifat semigrup Qfuzzy Smarandache. Selanjutnya, sifat-sifat yang telah diperoleh akan dibuktikan. Hasil dari penelitian ini adalah struktur baru tentang ring dan ideal Q-fuzzy Smarandache beserta sifat-sifatnya.
\end{abstract}

Kata Kunci: ring fuzzy Smarandache, idealfuzzy Smarandache, ring Q-fuzzy Smarandache, ideal $Q$ fuzzy Smarandache.

\begin{abstract}
Abstract algebra is the algebra science discusses the algebraic structure. One of the extensions of the concept of algebraic structure is fuzzy algebra. The development of fuzzy algebra has been widely researched, including Smarandache fuzzy ring and Smarandache fuzzy ideal. Smarandache ring is a generalization of the ring that is defined as a ring $R$ that has a proper subset $A \subset R$ such that $A$ is field and Smarandache ideal is defined as an ideal $A$ of $R$ that has a proper subset $X \subset A$ such that $X$ is field. This research aims to develop Smarandache $Q$-fuzzy algebra because currently there is a few related to these theories. These problems are then used to build new structures on the Smarandache $Q$-fuzzy ring, Smarandache Q-fuzzy ideal and their properties. This new structure is formed on the basis of the definition of the Smarandache fuzzy ring and Smarandache fuzzy ideal. Then, the properties of the concept of Smarandache Q-fuzzy semigroups. Furthermore, properties that have been obtained will be proved. The results of this research is the new structure of Smarandache $Q$-fuzzy ring, Smarandache $Q$ fuzzy ideal and their properties.
\end{abstract}

Keywords: Smarandache ring, Smarandache fuzzy ring, Smarandache $Q$-fuzzy ring, Smarandache fuzzy ideal, Smarandache $Q$-fuzzy ideal

\section{Pendahuluan}

Aljabar abstrak adalah ilmu aljabar yang membahas tentang struktur aljabar diantaranya, semigrup, grup, ring dan masih banyak lainnya. Pengembangan konsep struktur aljabar telah berkembang pesat salah satunya adalah struktur aljabar Smarandache yang diperkenalkan oleh 
Padilla [6] pada tahun 1998 dengan mengikuti sebuah paper yang ditulis oleh Smarandache Florentin dengan judul Special Algebraic Structures. Pada tahun 2012 Kandasamy [2] mengembangkan teori tersebut. Salah satunya adalah ring Smarandache yang didefinisikan sebagai suatu ring $R$ dengan himpunan bagian sejati $A \subset R$ sedemikian sehingga $A$ adalah field dan ideal Smarandache yang didefinisikan sebagai suatu ideal $A$ dari $R$ dengan himpunan bagian sejati $X \subset A$ sedemikian sehingga $A$ adalah field. Selanjutnya, pada tahun 2009 Srinivas dan Rao [11] memperkenalkan paper yang berjudul "On Smarandache Rings". Dalam paper tersebut Srinivas dan Rao membentuk struktur baru ring Smarandache yang didefinisikan sebagai suatu ring $R$ dengan setiap elemen $x \in R$ terdapat $a$ (bilangan bulat positif terkecil) $n(x)>1$ sedemikian sehingga $x^{n(x)}=x$ serta Maysuri [5] pada tahun 2011 membahas Smarandache Ring Reguler beserta sifat-sifatnya.

Selain struktur aljabar Smarandache, para peneliti telah mengembangkan penelitian terkait struktur aljabar fuzzy. Pada tahun 1982, Liu [4] membahas subgrup invariant fuzzy, ideal fuzzy di ring beserta sifat-sifatnya. Selanjutnya, Sebastian, dkk [9] pada tahun 2012 membahas ideal fuzzy dan ring fuzzy pada general ring, Kandasamy [3] pada tahun 2003 membahas ring fuzzy Smarandache yang didefinisikan sebagai himpunan bagian fuzzy $\mu$ pada $R$ (ring Smarandache), dengan pemetaan $\mu: R \rightarrow[0,1]$ sedemikian sehingga $\mu$ yang dibatasi pada $A$ memenuhi aksioma tertentu. Ring fuzzy Smarandache dinotasikan sebagai (ring FS). Begitu pula dengan ideal fuzzy Smarandache yang didefinisikan sebagai himpunan bagian fuzzy $\mu$ pada $R$ (ring), dengan pemetaan $\mu: R \rightarrow[0,1]$ sedemikian sehingga $\mu$ yang dibatasi pada $A$ dan $X$ memenuhi aksioma tertentu serta Utama dan Karyati [12] pada tahun 2016 membahas struktur fuzzy ring dengan memanfaatkan subhimpunan level $\mu_{t}$.

Pada tahun 2009 di dalam paper Solairaju dan Nagrajan [10] dibahas grup Q-fuzzy beserta sifat-sifatnya, Priya, dkk [7] pada tahun 2013 membahas subgrup Q-fuzzy, subgrup normal Q-fuzzy, koset kanan dan kiri Q-fuzzy, homomorfisma Q-fuzzy dan sifat-sifatnya, Sarala dan Suganya [8] pada tahun 2015 membahas Q-fuzzy soft ring beserta sifat-sifatnya. Selanjutnya, pada tahun 2016 Doss dan Suganya [1] memperkenalkan suatu struktur yang diberi nama Smarandache Q-Fuzzy Semigroups. Dalam paper tersebut dibahas mengenai semigrup dan semigrup normal Q-fuzzy Smarandache beserta sifat-sifatnya. Tujuan penelitian ini untuk mengembangkan struktur aljabar Q-fuzzy Smarandache karena belum banyak penelitian terkait struktur tersebut. Salah satu pengembangan yang penulis lakukan adalah dengan cara membangun struktur baru tentang ring dan ideal Q-fuzzy Smarandache beserta sifat-sifatnya berdasarkan definisi di dalam buku [3] dan sifat-sifat yang berlaku di dalam paper [1] sebagai 
bahan penelitian. Selanjutnya, membuktikan sifat-sifat dari ring dan ideal Q-fuzzy Smarandache. Sehingga, hasil dari penelitian ini adalah struktur baru tentang ring dan ideal Q-fuzzy Smarandache beserta sifat-sifatnya.

\section{Metode Penelitian}

Metode penelitian yang digunakan dalam penelitian ini adalah studi literatur terhadap berbagai pustaka baik berupa buku, paper maupun jurnal ilmiah yang berkaitan. Langkah awal yang dilakukan dalam penelitian ini yaitu dengan mempelajari teori terkait ring Smarandache, ideal Smarandache, ring fuzzy Smarandache dan ideal fuzzy Smarandache kemudian membangun struktur baru tentang ring dan ideal Q-fuzzy Smarandache serta membuktikan beberapa teorema yang terkait. Berikut diberikan beberapa definisi dan teorema yang mendukung dalam penelitian.

2.1 Ring Smarandache dan Ideal Smarandache

Pada subbab ini akan diberikan definisi dari ring Smarandache dan ideal Smarandache, yang menjadi dasar dalam pembentukan struktur baru tentang ring dan ideal Q-fuzzy Smarandache.

Definisi 1 [2] Ring $(R,+,$.$) disebut ring Smaradanche jika terdapat himpunan bagian sejati$ $A \subset R$ sedemikian sehingga $A$ adalah field.

Definisi 2 [2] Misalkan $(R,+,$.$) adalah ring dan (A,+,$.$) merupakan subring dari R$. Ideal Smarandache didefinisikan sebagai ideal A yang memuat himpunan bagian sejati $X \subset A$ dan membentuk field.

2.2 Ring Fuzzy Smarandache dan Ideal Fuzzy Smarandache

Dalam subbab ini akan diberikan definisi tentang teori ring fuzzy Smarandache dan ideal fuzzy Smarandache sebagai teori dasar dalam hasil dan pembahasan.

Definisi 3 [3] Misalkan $R$ adalah ring Smarandache. Himpunan bagian fuzzy $\mu$ pada $R$ disebut ring fuzzy Smarandache jika $\mu: R \rightarrow[0,1]$ sedemikian sehingga $\mu$ yang dibatasi pada $A$ memenuhi aksioma berikut:

1. $\mu_{A}(x-y) \geq \min \left\{\mu_{A}(x), \mu_{A}(y)\right\}$

2. $\mu_{A}\left(x y^{-1}\right) \geq \min \left\{\mu_{A}(x), \mu_{A}(y)\right\}$

$y \neq 0, \forall x, y \in A$.

Definisi 4 [3] Misalkan $R$ adalah ring Smarandache. Himpunan bagian fuzzy $\mu$ di $R$ disebut ideal fuzzy Smarandache jika $\mu: R \rightarrow[0,1]$ sedemikian sehingga $\mu$ memenuhi beberapa kondisi, 
1. $R$ memiliki himpunan bagian sejati $A \subset R$ dan $\mu$ dibatasi pada $A$ yang memenuhi aksioma berikut,

i. $\mu_{A}(x-y) \geq \min \left\{\mu_{A}(x), \mu_{A}(y)\right\}$

ii. $\mu_{A}(x y) \geq \max \left\{\mu_{A}(x), \mu_{A}(y)\right\}$

$\forall x, y \in A$

2. A memuat himpunan bagian sejati $P \subset A$ sedemikian sehingga $P$ adalah field dan $\mu$ dibatasi pada $P$ yang memenuhi aksioma berikut,

i. $\mu_{X}(x-y) \geq \min \left\{\mu_{X}(x), \mu_{X}(y)\right\}$

ii. $\mu_{X}(x y) \geq \max \left\{\mu_{X}(x), \mu_{X}(y)\right\}$

$\forall x, y \in X$

2.3 Semigrup Q-Fuzzy Smarandache

Dalam subbab ini akan diberikan teorema-teorema dalam paper [1] yang akan dijadikan bahan rujukan terkait pembentukan sifat-sifat (teorema) dalam struktur baru ring Q-fuzzy Smarandache dan ideal Q-fuzzy Smarandache.

Proposisi 1 [1] Misalkan $H$ adalah semigrup Smarandache dan $Q$ merupakan himpunan tidak kosong. Jika $\mu$ adalah semigrup QFS maka berlaku,

i. $\quad \mu_{G}(e, q) \geq \mu_{G}(x, q)$ untuk e adalah elemen identitas dari $G$

ii. $\mu_{G}\left(x^{-1}, q\right) \geq \mu_{G}(x, q)$ untuk setiap $x \in G$ dan $q \in Q$

Teorema 2 [1] Misalkan $H$ adalah semigrup Smarandache dan $Q \neq \emptyset$. $\mu$ adalah semigrup $Q$ fuzzy Smarandache. Jika $\mu_{G}\left(x y^{-1}, q\right)=\mu_{G}(e, q)$ maka $\mu_{G}(x, q)=\mu_{G}(y, q)$ untuk setiap $x, y \in$ $G$ dan $q \in Q$.

Teorema 3 [1] Misalkan $H$ adalah semigrup Smarandache dan $Q \neq \varnothing$. $\mu$ adalah semigrup $Q$ fuzzy Smarandache. jika $\mu_{G}\left(x y^{-1}, q\right)=1$ maka $\mu_{G}(x, q)=\mu_{G}(y, q)$ untuk setiap $x, y \in G$ dan $q \in Q$.

Teorema 4 [1] Irisan dari dua semigrup Q-fuzzy Smarandache juga merupakan semigrup $Q$ fuzzy Smarandache.

Teorema 5 [1] Misalkan $H$ adalah semigrup Smarandache dan $Q \neq \varnothing$. Jika $\mu$ adalah semigrup $Q$-fuzzy Smarandache maka $\mu^{C}$ juga merupakan semigrup Q-fuzzy Smarandache.

\section{Hasil dan Pembahasan}

Dalam bab ini akan dibangun struktur baru tentang ring dan ideal Q-fuzzy Smarandache yang dirujuk dalam buku [3]. Sedangkan sifat-sifat yang diperoleh dalam struktur baru tersebut akan dirujuk berdasarkan paper [1] sebagaimana yang telah diuraikan dalam subbab 2.3. 


\subsection{Ring Q-Fuzzy Smarandache}

Definisi 5 Misalkan $R$ adalah ring Smarandache. Himpunan bagian $Q$-fuzzy $\mu$ dari $R$ disebut ring $Q$-fuzzy Smarandache jika $\mu: R \times Q \rightarrow[0,1]$ sedemikian sehingga $\mu$ yang dibatasi pada $A \times$ $Q$ memenuhi aksioma berikut,

1. $\mu_{A}(x-y, q) \geq \min \left\{\mu_{A}(x, q), \mu_{A}(y, q)\right\}$

2. $\mu_{A}\left(x y^{-1}, q\right) \geq \min \left\{\mu_{A}(x, q), \mu_{A}(y, q)\right\}$

$y \neq 0, \forall x, y \in A$ dan $q \in Q$

Ring Q-fuzzy Smarandache dinotasikan sebagai (ring QFS)

Contoh 1 Diberikan himpunan bilangan bulat $\mathbb{Z}_{6}=\{\hat{0}, \hat{1}, \hat{2}, \hat{3}, \hat{4}, \hat{5}\}$ dengan operasi penjumlahan dan perkalian $\left(\mathbb{Z}_{6},+, \times\right)$ merupakan ring dan $Q=\{1,2\}$. Didefinisikan pemetaan $\mu: Z_{6} \times Q \rightarrow$ $[0,1]$ sebagai berikut:

$$
\mu(x, q)=\left\{\begin{aligned}
0.5 \text { jika } x & =(\hat{1}, 1)(\hat{1}, 2)(\hat{3}, 2)(\hat{5}, 2) \\
0.8 \text { jika } x & =(\hat{2}, 1)(\hat{4}, 1)(\hat{2}, 2)(\hat{4}, 2) \\
1 \text { jika } x & =(\hat{0}, 1)(\hat{3}, 1)(\hat{5}, 1)(\hat{0}, 2)
\end{aligned}\right.
$$

Jelas bahwa $\mathbb{Z}_{6}$ memiliki himpunan bagian sejati $A=\{\hat{0}, \hat{2}, \hat{4}\}$ adalah field sehingga, dapat dengan mudah diperoleh bahwa $\mu$ yang dibatasi pada $(A \times Q)$ memenuhi aksioma-aksiomanya. Oleh karena itu $\mu$ adalah ring Q-fuzzy Smarandache.

Contoh 2 Diberikan himpunan bilangan kompleks dengan operasi penjumlahan dan perkalian $(\mathbb{C},+, \times)$ adalah ring dan $Q=\{1,2\}$. Pilih subset sejati dari $\mathbb{C}$ yaitu, bilangan real $\mathbb{R}$ dan didefinisikan pemetaan $\mu: \mathbb{C} \times Q \rightarrow[0,1]$ sebagai berikut

$$
\mu(x, q)=\frac{e^{-(x)^{2}}}{q}
$$

Sedemikian sehingga $\mu$ yang dibatasi pada $\mathbb{R} \times Q$ memenuhi aksioma

$\mu_{R}(x-y, q) \geq \min \left\{\mu_{R}(x, q), \mu_{R}(y, q)\right\}$ dan $\mu_{R}\left(x y^{-1}, q\right) \geq \min \left\{\mu_{R}(x, q), \mu_{R}(y, q)\right\}$

Akan ditunjukkan bahwa $\mu$ adalah ring QFS dari $\mathbb{C}$ yang memenuhi,

$\mu_{\mathbb{R}}(x-y, q) \geq \min \left\{\mu_{\mathbb{R}}(x, q), \mu_{\mathbb{R}}(y, q)\right\}, \mu_{\mathbb{R}}\left(x y^{-1}, q\right) \geq \min \left\{\mu_{\mathbb{R}}(x, q), \mu_{\mathbb{R}}(y, q)\right\}$.

Hasil: Ambil $x, y \in \mathbb{R}$ dengan $x \geq y$ dan $Q=\{1,2\}$. Akan ditunjukkan bahwa $\mu$ adalah ring QFS dari $\mathbb{C}$. Sekarang perhatikan bahwa,

a. $\mu_{R}(x-y, q) \geq \min \left\{\mu_{R}(x, q), \mu_{R}(y, q)\right\}$

$$
\begin{aligned}
& \frac{e^{-\left((x-y)^{2}\right)}}{q} \geq \min \left\{\frac{e^{-\left((x)^{2}\right)}}{q}, \frac{e^{-\left((y)^{2}\right)}}{q}\right\} . \\
& e^{-\frac{\left((z)^{2}\right)}{q}} \geq \min \left\{\frac{e^{-\left((x)^{2}\right)}}{q}, \frac{e^{-\left((y)^{2}\right)}}{q}\right\} .
\end{aligned}
$$

b. $\mu_{R}\left(x y^{-1}, q\right) \geq \min \left\{\mu_{R}(x, q), \mu_{R}(y, q)\right\}$ 


$$
\begin{aligned}
& e^{-\frac{\left(\left(x y^{-1}\right)^{2}\right)}{q}} \geq \min \left\{e^{-\frac{\left((x)^{2}\right)}{q}}, e^{\left.-\frac{\left((y)^{2}\right)}{q}\right\} .}\right. \\
& e^{-\frac{(z)^{2}}{q}} \geq \min \left\{e^{-\frac{\left((x)^{2}\right)}{q}}, e^{-\frac{\left((y)^{2}\right)}{q}}\right\} .
\end{aligned}
$$

Karena kondisi i dan ii terpenuhi maka $\mu$ adalah ring QFS dari $\mathbb{R}$

Begitu pula jika $x \leq y$ akan memenuhi aksioma-aksioma dari ring QFS dari $\mathbb{R}$.

Proposisi 6 Misalkan $(R,+,$.$) adalah ring Smarandache dengan himpunan bagian sejati A$ adalah field. Jika $\mu$ adalah ring QFS dari $R$ maka berlaku,

1. $\mu_{A}(0, q) \geq \mu_{A}(x, q)$

2. $\mu_{A}(1, q) \geq \mu_{A}(x, q)$

3. $\mu_{A}(-x, q) \geq \mu(x, q)$

untuk setiap $0,1, x,-x \in A$ dengan 0,1 adalah elemen identitas dari $A$ dan $q \in Q$.

Bukti: Diketahui bahwa $R$ adalah ring Smarandache dan $\mu$ merupakan ring QFS dari $R$. Akan ditunjukkan bahwa ketiga sifat tersebut terpenuhi. Ambil $0,1, x,-x \in A$ dan $q \in Q$.

1. $\mu_{A}(0, q)=\mu_{A}(x+(-x), q)$

$$
\begin{aligned}
& \geq \min \left\{\mu_{A}(x, q), \mu_{A}(-x, q)\right\} \\
& =\min \left\{\mu_{A}(x, q), \mu_{A}(x, q)\right\} \\
& =\mu_{A}(x, q)
\end{aligned}
$$

2. $\mu_{A}(1, q)=\mu_{A}\left(x \cdot x^{-1}, q\right)$

$$
\begin{aligned}
& \geq \min \left\{\mu_{A}(x, q), \mu_{A}\left(x^{-1}, q\right)\right\} \\
& =\min \left\{\mu_{A}(x, q), \mu_{A}(x, q)\right\} \\
& =\mu_{A}(x, q)
\end{aligned}
$$

3. $\mu_{A}(-x, q)=\mu_{A}(0+(-x), q)$

$$
\begin{aligned}
& \geq \min \left\{\mu_{A}(0, q), \mu_{A}(-x, q)\right\} \\
& =\min \left\{\mu_{A}(0, q), \mu_{A}(x, q)\right\} \\
& =\mu_{A}(x, q)
\end{aligned}
$$

Jadi terbukti bahwa ketiga sifat di atas telah terpenuhi, sehingga $\mu$ merupakan ring QFS.

Teorema 7 Misalkan $(R,+,$.$) adalah ring Smarandache dengan himpunan bagian sejati A$ adalah field dan $\mu$ adalah ring QFS dari $R$.

1. Jika $\mu_{A}(x-y, q)=\mu_{A}(0, q) \operatorname{maka} \mu_{A}(x, q)=\mu_{A}(y, q)$

2. Jika $\mu_{A}\left(x y^{-1}, q\right)=1$ maka $\mu_{A}(x, q)=\mu_{A}(y, q)$

untuk setiap $x, y \in A$ dan $q \in Q$ 
Bukti: Diketahui bahwa $R$ adalah ring Smarandache dan $\mu$ merupakan ring QFS. Akan dibuktikan bahwa $\mu_{A}(x, q)=\mu_{A}(y, q)$ pada kedua sifat di atas. Ambil $x, y \in A$ dan $q \in Q$.

1. $\mu_{A}(x, q)=\mu_{A}(x-y+y, q)$

$$
\begin{aligned}
& \geq \min \left\{\mu_{A}(x-y, q), \mu_{A}(y, q)\right\} \\
& =\min \left\{\mu_{A}(0, q), \mu_{A}(y, q)\right\} \\
& =\mu_{A}(y, q) .
\end{aligned}
$$

Dan

$$
\begin{aligned}
\mu_{A}(y, q) & =\mu_{A}(y-x+x, q) \\
& \geq \min \left\{\mu_{A}(y-x, q), \mu_{A}(x, q)\right\} \\
& =\min \left\{\mu_{A}(y-x)^{-1}, \mu_{A}(x, q)\right\} \\
& =\min \left\{\mu_{A}(x-y), \mu_{A}(x, q)\right\} \\
& =\min \left\{\mu_{A}(0, q), \mu_{A}(x, q)\right\} \\
& =\mu_{A}(x, q)
\end{aligned}
$$

2. $\mu_{A}(x, q)=\mu_{A}\left(x y^{-1} y, q\right)$

$$
\begin{aligned}
& \geq \min \left\{\mu_{A}\left(x y^{-1}, q\right), \mu_{A}(y, q)\right\} \\
& =\min \left\{\mu_{A}(1, q), \mu_{A}(y, q)\right\} \\
& =\mu_{A}(y, q) .
\end{aligned}
$$

Dan

$$
\begin{aligned}
\mu_{A}(y, q) & =\mu_{A}\left(y^{-1}, q\right) \\
& =\mu_{A}\left(x^{-1} x y^{-1}, q\right) \\
& \geq \min \left\{\mu_{A}\left(x^{-1}, q\right), \mu_{A}\left(x y^{-1}, q\right)\right\} \\
& =\min \left\{\mu_{A}\left(x^{-1}, q\right), 1\right\} \\
& =\min \left\{\mu_{A}\left(x^{-1}, q\right)\right\} \\
& =\mu_{A}(x, q)
\end{aligned}
$$

Terbukti bahwa $\mu_{A}(x, q)=\mu_{A}(y, q)$, untuk setiap $x, y \in A$ dan $q \in Q$

Teorema 8 Misalkan $(R,+,$.$) adalah ring Smarandache dengan himpunan bagian sejati A$ adalah field dan $\mu$ adalah ring QFS dari R. Jika $\mu_{A}\left(x y^{-1}, q\right)=e \operatorname{maka} \mu_{A}(x, q)=\mu_{A}(y, q)$, untuk setiap $x, y \in A$ dan $q \in Q$.

Bukti: Bukti analog dengan Teorema 2

Teorema 9 Misalkan $(R,+,$.$) adalah ring Smarandache dengan himpunan bagian sejati A dan$ $B$ berturut-turut adalah field. Dimisalkan pula bahwa $\mu$ dan $\beta$ keduanya merupakan ring QFS. Irisan dari dua ring QFS juga merupakan ring QFS. 
Bukti: Diketahui $(R,+,$.$) adalah ring Smaradance dan \mu$ dan $\beta$ adalah dua ring QFS. Akan dibuktikan bahwa irisan dari keduanya adalah ring QFS.

Ambil $x, y \in A$ dan $q \in Q$

i. $\left(\mu_{A} \cap \beta_{A}\right)(x-y, q)=\min \left\{\mu_{A}(x-y, q), \beta_{A}(x-y, q)\right\}$

$$
\begin{aligned}
\geq \min \{ & \left.\min \left\{\mu_{A}(x, q), \mu_{A}(y, q)\right\}, \min \left\{\beta_{A}(x, q), \beta_{A}(y, q)\right\}\right\} \\
& =\min \left\{\min \left\{\mu_{A}(x, q), \beta_{A}(x, q)\right\}, \min \left\{\mu_{A}(y, q), \beta_{A}(y, q)\right\}\right\} \\
& =\min \left\{\left(\mu_{A} \cap \beta_{A}\right)(x, q),\left(\mu_{A} \cap \beta_{A}\right)(y, q)\right\}
\end{aligned}
$$

ii. $\left(\mu_{A} \cap \beta_{A}\right)\left(x y^{-1}, q\right)=\min \left\{\mu_{A}\left(x y^{-1}, q\right), \beta_{A}\left(x y^{-1}, q\right)\right\}$

$$
\begin{aligned}
\geq \min \{ & \left.\min \left\{\mu_{A}(x, q), \mu_{A}(y, q)\right\}, \min \left\{\beta_{A}(x, q), \beta_{A}(y, q)\right\}\right\} \\
& =\min \left\{\min \left\{\mu_{A}(x, q), \beta_{A}(x, q)\right\}, \min \left\{\mu_{A}(y, q), \beta_{A}(y, q)\right\}\right\} \\
& =\min \left\{\left(\mu_{A} \cap \beta_{A}\right)(x, q),\left(\mu_{A} \cap \beta_{A}\right)(y, q)\right\}
\end{aligned}
$$

Berdasarkan (i) dan (ii) terpenuhi, maka terbukti bahwa $\mu \cap \beta$ merupakan ring QFS.

Teorema 10 Misalkan $(R,+,$.$) adalah ring Smarandache dengan himpunan bagian sejati A$ adalah field. Jika $\mu$ adalah ring QFS maka $\mu^{c}$ juga merupakan ring QFS.

Bukti: Diketahui $(R,+,$.$) adalah ring Smaradance dan \mu$ adalah ring QFS. Akan ditunjukkan bahwa $\mu^{c}$ juga merupakan ring QFS.

Ambil $x, y \in A$ dan $q \in Q$

a. $\mu_{A}^{c}(x-y, q)=1-\mu_{A}(x-y, q)$

$$
\begin{aligned}
& \leq 1-\min \left\{\mu_{A}(x, q), \mu_{A}(y, q)\right\} \\
& =\max \left\{1-\mu_{A}(x, q), 1-\mu_{A}(y, q)\right\} \\
& =\max \left\{\mu_{A}^{c}(x, q), \mu_{A}^{c}(y, q)\right\} .
\end{aligned}
$$

b. $\mu_{A}^{c}\left(x y^{-1}, q\right)=1-\mu_{A}\left(x y^{-1}, q\right)$

$$
\begin{aligned}
& \leq 1-\min \left\{\mu_{A}(x, q), \mu_{A}(y, q)\right\} \\
& =\max \left\{1-\mu_{A}(x, q), 1-\mu_{A}(y, q)\right\} \\
& =\max \left\{\mu_{A}^{c}(x, q), \mu_{A}^{c}(y, q)\right\} .
\end{aligned}
$$

3.2 Ideal Q-Fuzzy Smarandache

Definisi 6 Misalkan $R$ adalah ring Smarandache. Himpunan bagian $Q$-fuzzy $\mu$ dari $R$ disebut ideal QFS dari $R$ jika $\mu: R \times Q \rightarrow[0,1]$ sedemikian sehingga $\mu$ memenuhi beberapa kondisi berikut,

1. $R$ memiliki himpunan bagian sejati $A \subset R$ dan $\mu$ dibatasi pada $A \times Q$ yang memenuhi aksioma berikut,

i. $\mu_{A}(x-y, q) \geq \min \left\{\mu_{A}(x, q), \mu_{A}(y, q)\right\}$

ii. $\mu_{A}(x y, q) \geq \max \left\{\mu_{A}(x, q), \mu_{A}(y, q)\right\}$ 
$\forall x, y \in A$ dan $q \in Q$

2. A memiliki himpunan bagian sejati $X$ sedemikian sehingga $X$ adalah field dan $\mu$ dibatasi pada $X \times Q$ memenuhi aksioma berikut,

i. $\mu_{X}(x-y, q) \geq \min \left\{\mu_{X}(x, q), \mu_{X}(y, q)\right\}$

ii. $\quad \mu_{X}\left(x y^{-1}, q\right) \geq \min \left\{\mu_{X}(x, q), \mu_{X}(y, q)\right\}$

$y \neq 0, \forall x, y \in X$ dan $q \in Q$

Contoh 3 Diberikan himpunan bilangan bulat $\mathbb{Z}_{12}=\{\hat{0}, \hat{1}, \hat{2}, \hat{3}, \hat{4}, \hat{5}, \ldots, \widehat{10}, \widehat{1}\}$ dengan operasi penjumlahan dan perkalian $\left(\mathbb{Z}_{12},+, \times\right)$ merupakan ring dan $Q=\{1\}$. Didefinisikan pemetaan $\mu: Z_{12} \times Q \rightarrow[0,1]$ sebagai berikut

$$
\mu(x, q)=\left\{\begin{array}{cl}
0.5 & \text { jika } x=(\hat{2}, 1)(\hat{6}, 1)(\widehat{10}, 1) \\
0.1 & \text { jika } x=(\hat{1}, 1)(\widehat{3}, 1)(\widehat{5}, 1)(\hat{7}, 1)(\widehat{9}, 1)(\widehat{11}, 1) \\
1 & \text { jika } x=(\hat{0}, 1)(\widehat{4}, 1)(\widehat{8}, 1)
\end{array}\right.
$$

Jelas bahwa $\mathbb{Z}_{12}$ memiliki ideal Smarandache yaitu $A=\{\hat{0}, \hat{2}, \hat{4}, \widehat{6}, \widehat{8}, \widehat{10}\}$ dan $X=\{\hat{0}, \widehat{4}, \widehat{8}\}$ merupakan field dari $A$ sehingga, dapat dengan mudah dibuktikan bahwa $\mu$ yang dibatasi pada $(A \times Q)$ dan $(X \times Q)$ memenuhi aksioma-aksiomanya. Oleh karena itu $\mu$ adalah ideal Q-fuzzy Smarandache.

Teorema 11 Misalkan $(R,+,$.$) adalah ring Smarandache. Misalkan pula bahwa (A,+,$. merupakan ideal Smarandache dari $R$ dengan $X \subset A$ sedemikian sehingga $X$ adalah field. Jika $\mu$ dan $\beta$ keduanya merupakan ideal QFS maka irisan dari dua ideal QFS juga merupakan ideal QFS.

Bukti: Diketahui $(R,+,$.$) adalah ring Smaradance dan (A,+,$.$) merupakan ideal Smarandache$ dari $R$ dengan $X \subset A$ sedemikian sehingga $X$ adalah field. Diketahui juga bahwa $\mu$ dan $\beta$ adalah dua ideal QFS. Akan dibuktikan bahwa irisan dari keduanya adalah ideal QFS.

a. Ambil $x, y \in A$ dan $q \in Q$

i. $\left(\mu_{A} \cap \beta_{A}\right)(x-y, q)=\min \left\{\mu_{A}(x-y, q), \beta_{A}(x-y, q)\right\}$

$$
\begin{aligned}
\geq \min \{ & \left.\min \left\{\mu_{A}(x, q), \mu_{A}(y, q)\right\}, \min \left\{\beta_{A}(x, q), \beta_{A}(y, q)\right\}\right\} \\
& =\min \left\{\min \left\{\mu_{A}(x, q), \beta_{A}(x, q)\right\}, \min \left\{\mu_{A}(y, q), \beta_{A}(y, q)\right\}\right\} \\
& =\min \left\{\left(\mu_{A} \cap \beta_{A}\right)(x, q),\left(\mu_{A} \cap \beta_{A}\right)(y, q)\right\}
\end{aligned}
$$

ii. $\left(\mu_{A} \cap \beta_{A}\right)(x y, q)=\max \left\{\mu_{A}(x y, q), \beta_{A}(x y, q)\right\}$

$$
\begin{aligned}
\geq \max & \left\{\max \left\{\mu_{A}(x, q), \mu_{A}(y, q)\right\}, \max \left\{\beta_{A}(x, q), \beta_{A}(y, q)\right\}\right\} \\
& =\max \left\{\max \left\{\mu_{A}(x, q), \beta_{A}(x, q)\right\}, \max \left\{\mu_{A}(y, q), \beta_{A}(y, q)\right\}\right\} \\
& =\max \left\{\left(\mu_{A} \cap \beta_{A}\right)(x, q),\left(\mu_{A} \cap \beta_{A}\right)(y, q)\right\}
\end{aligned}
$$


b. Ambil $x, y \in X$ dan $q \in Q$

i. $\left(\mu_{X} \cap \beta_{X}\right)(x-y, q)=\min \left\{\mu_{X}(x-y, q), \beta_{X}(x-y, q)\right\}$

$$
\begin{aligned}
\geq \min & \left\{\min \left\{\mu_{X}(x, q), \mu_{X}(y, q)\right\}, \min \left\{\beta_{X}(x, q), \beta_{X}(y, q)\right\}\right\} \\
& =\min \left\{\min \left\{\mu_{X}(x, q), \beta_{X}(x, q)\right\}, \min \left\{\mu_{X}(y, q), \beta_{X}(y, q)\right\}\right\} \\
& =\min \left\{\left(\mu_{X} \cap \beta_{X}\right)(x, q),\left(\mu_{X} \cap \beta_{X}\right)(y, q)\right\}
\end{aligned}
$$

ii. $\left(\mu_{X} \cap \beta_{X}\right)\left(x y^{-1}, q\right)=\min \left\{\mu_{X}\left(x y^{-1}, q\right), \beta_{X}\left(x y^{-1}, q\right)\right\}$

$$
\begin{aligned}
\geq \min & \left\{\min \left\{\mu_{X}(x, q), \mu_{X}(y, q)\right\}, \min \left\{\beta_{X}(x, q), \beta_{X}(y, q)\right\}\right\} \\
& =\min \left\{\min \left\{\mu_{X}(x, q), \beta_{X}(x, q)\right\}, \min \left\{\mu_{X}(y, q), \beta_{X}(y, q)\right\}\right\} \\
& =\min \left\{\left(\mu_{X} \cap \beta_{X}\right)(x, q),\left(\mu_{X} \cap \beta_{X}\right)(y, q)\right\}
\end{aligned}
$$

Berdasarkan (a) dan (b) terpenuhi, maka terbukti bahwa $\mu \cap \beta$ merupakan ideal QFS.

Teorema 12 Misalkan $(R,+,$.$) adalah ring Smarandache. Misalkan pula bahwa (A,+,$. merupakan ideal Smarandache dari $R$ dengan $X \subset A$ sedemikian sehingga $X$ adalah field. Jika $\mu$ adalah ideal QFS maka $\mu^{c}$ juga merupakan ideal QFS.

Bukti: Diketahui $(R,+,$.$) adalah ring Smaradance dan (A,+,$.$) merupakan ideal Smarandache$ dari $R$ dengan $X \subset A$ sedemikian sehingga $X$ adalah field. Akan ditunjukkan bahwa $\mu^{c}$ juga merupakan ideal QFS.

Ambil $x, y \in A$ dan $q \in Q$

a. $\mu_{A}^{c}(x-y, q)=1-\mu_{A}(x-y, q)$

$$
\begin{aligned}
& \leq 1-\min \left\{\mu_{A}(x, q), \mu_{A}(y, q)\right\} \\
& =\max \left\{1-\mu_{A}(x, q), 1-\mu_{A}(y, q)\right\} \\
& =\max \left\{\mu_{A}^{c}(x, q), \mu_{A}^{c}(y, q)\right\} .
\end{aligned}
$$

b. $\mu_{A}^{c}\left(x y^{-1}, q\right)=1-\mu_{A}\left(x y^{-1}, q\right)$

$$
\begin{aligned}
& \leq 1-\max \left\{\mu_{A}(x, q), \mu_{A}(y, q)\right\} \\
& =\min \left\{1-\mu_{A}(x, q), 1-\mu(y, q)\right\} \\
& =\min \left\{\mu_{A}^{c}(x, q), \mu^{c}(y, q)\right\}
\end{aligned}
$$

Dan Ambil $x, y \in X$ dan $q \in Q$

c. $\mu_{X}^{c}(x-y, q)=1-\mu_{X}(x-y, q)$

$$
\begin{aligned}
& \leq 1-\min \left\{\mu_{X}(x, q), \mu_{X}(y, q)\right\} \\
& =\max \left\{1-\mu_{X}(x, q), 1-\mu_{X}(y, q)\right\} \\
& =\max \left\{\mu_{X}^{c}(x, q), \mu_{X}^{c}(y, q)\right\} .
\end{aligned}
$$

d. $\mu_{X}^{c}\left(x y^{-1}, q\right)=1-\mu_{X}\left(x y^{-1}, q\right)$

$$
\begin{aligned}
& \leq 1-\max \left\{\mu_{X}(x, q), \mu_{X}(y, q)\right\} \\
& =\min \left\{1-\mu_{X}(x, q), 1-\mu_{X}(y, q)\right\}
\end{aligned}
$$




$$
=\min \left\{\mu_{X}^{c}(x, q), \mu_{X}^{c}(y, q)\right\}
$$

Jadi $\mu^{c}$ merupakan ideal QFS.

\section{Simpulan}

Dalam penelitian ini, telah dibentuk struktur baru tentang ring Q-fuzzy Smarandache dan ideal Q-fuzzy Smarandache dengan contoh-contoh yang mendukung beserta sifat-sifat yang telah dibuktikan.

\section{Daftar Pustaka}

[1] Doss, A.R and Suganya, S., "Smarandache Q-Fuzzy Semigroups". Advances in Fuzzy Mathematics, vol. 11, no. 1, pp. 89-97, 2016.

[2] Kandasamy, W.B., Smarandache Rings. American Research Press Rehoboth, 2002.

[3] Kandasamy, W.B., Smarandache Fuzzy Algebra. American Research Press Rehoboth, 2003.

[4] Liu, J.W., "Fuzzy Invariant Subgroups and Fuzzy Ideals". Fuzzy Sets and Systems, 8, pp.133-139, 1982

[5] Maysuri, N., Smarandache Ring Reguler. Skripsi, Pekanbaru: Universitas Islam Negeri Sultan Syarif Kasim Riau Pekanbaru. 2011.

[6] Padila, R., "Smarandache Algebraic Structure". Bulletin of Pure and Applied Sciences, vol. 17E, no. 1, pp. 119-121, 1998.

[7] Priya, T., Ramachandran, T, and Nagalaksmi, K.T., "On Q-Fuzzy Normal Subgroups". International Journal of Computer \& Organization Trends, vol. 3, no. 11, pp. 574-578, 2013.

[8] Sarala, N and Suganya, B., "Q-Fuzzy Soft Ring". International Journal of Engineering Research \& Thecnology (IJERT), vol. 4, no. 2, pp. 879-882, 2015.

[9] Sebastian, S., Jacob, K.M, and Mary, M.V., "Fuzzy Ideals and Rings". J. Comp \& Math, vol. 3, no. 1, pp. 115-120, 2012.

[10] Solairaju, A and Nagarajan, R., "A New Structure and Contruction of Q-Fuzzy Groups". Advances in Fuzzy Mathematics, vol. 4, no. 1, pp. 23-29, 2009.

[11] Srinivas, T and Rao, S.C., "Smarandache Rings". Scientia Magna, vol. 5, no. 4, pp. 117$124,2009$.

[12] Utama, C.R dan Karyati., "Ring Fuzzy dan Sifat-Sifatnya". J. Sains Dasar, vol. 5, no. 1, pp. 28-39, 2016. 